\title{
Analysis of RC Deep Beams Considering the Shear Deformations and Bar-concrete Interaction
}

\author{
Seyed Shaker Hashemi ${ }^{1 *}$, Kabir Sadeghi ${ }^{2}$, Saeid Javidi ${ }^{1}$, Mahmoud Malakouti $^{1}$ \\ ${ }^{1}$ Department of Civil Engineering, Persian Gulf University, Shahid Mahini Street, 75169-13817 Bushehr, Iran \\ ${ }^{2}$ Department of Civil Engineering, Near East University, ZIP Code: 99138, Lefkosa, TRNC, Mersin 10, Turkey \\ * Corresponding author, e-mail: sh.hashemi@pgu.ac.ir
}

Received: 09 April 2020, Accepted: 04 September 2020, Published online: 14 October 2020

\begin{abstract}
In this paper, reinforced concrete (RC) deep beams (DBs) have been analyzed numerically and a new approach is proposed to the nonlinear numerical modeling of such structural members. The effect of shear deformations and the interaction between reinforcing steel bar and concrete are considered in modeling and analysis. In order to consider the effect of shear deformations, the Timoshenko beam theory has been applied to formulate the analysis method. In the modeling, the RC DB is divided into several sub-elements which are composed of concrete and reinforcing steel bars. Individual degrees of freedom have been assigned to each reinforcing steel bar. Thus, each reinforcing steel bar is able to slip relative to its surrounding concrete and the bond effect is simulated by nonlinear springs. To consider the interaction between reinforcing steel bar and concrete, the concrete segment acts as a beam element, and each reinforcing steel bar acts as a truss element. The reliability of this method has been confirmed by comparing the obtained results from the numerical analysis and the results of the experimental pushover test.
\end{abstract}

Keywords

nonlinear analysis, Timoshenko beam theory, reinforcing steel bar-concrete interaction, shear deformation, reinforced concrete deep beam

\section{Introduction}

Reinforced concrete (RC) deep beams (DBs) are key safe structural systems carrying heavy loads over short spans. They are usually a part of complex concrete structures. RC DBs have a wide usage as the structural members in highrise buildings and bridges, although it is not easy to predict their behavior. Several analytical models have been proposed for the nonlinear analysis of RC DBs, but there is no general method to predict the overall behavior of all kinds of them. This is because many parameters affect the shear behavior of RC DBs [1]. The main parameters affecting the behavior of DBs such as geometry, concrete strength and reinforcement have been studied. The results show that the mentioned parameters have significant effects on deformation, crack pattern, principal stresses, ultimate load and failure mechanism of DBs [2]. In DBs, the length of the shear span is less than twice of the effective depth of the beam, so due to disturbed regions (D-region), the Euler-Bernoulli beam theory cannot be applied because the stresses distributed irregularly. Considering the effect of shear deformations has a significant impact on the behavior of deep beams, and ignoring it causes a considerable error in predicting the shear capacity [3]. Rogowsky et al. [4] presented a classification for RC DBs considering the ratio of shear span to effective depth. RC DB members are usually reinforced by an orthogonal steel mesh, and it is needed to consider the nonlinear distribution of strain in D-regions for modeling their nonlinear behavior. A suitable nonlinear model should be capable of considering the mentioned effect. The strut and tie model (STM) is one of the popular methods which considers the effect of shear deformations [5]. American concrete institute (ACI) proposes an STM model to analyze and design the RC DBs [6]. STM is based on the lower bond theorem [7]. According to ACI code, STM is an appropriate method to analyze and design the RC members which do not follow the EulerBernoulli beam theory. Although this has been an approximated and conservative model, it is accepted worldwide [8]. Almási [9] indicated that the alternative STMs are useful since there are turbulent places which have a noticeable influence on the cracks. 
Smith and Vantsiotis [10] studied the behavior and ultimate shear resistance of RC DBs. Based on their research, the presence of vertical steel bars mesh improves the performance of DBs under shear stresses, while the effect of horizontal steel bars mesh does not have a significant impact on the shear performance and the ultimate shear strength. According to research carried out by Breña and Roy [11], regardless of the depth of beams, the shear strength of DBs increases when the ratio of shear span to effective depth decreases. Several researchers have studied the shear failure mechanism and shear strength of DBs [12]. Different failure mechanisms have been observed in DBs by doing experiments. Because of the variety of failure mechanisms, it is hard to predict the failure mechanism and ultimate resistance. The failure mode of RC DBs has been investigated by Yu et al. [13] for the case of DBs damaged by corrosion in a chloride environment. The results show that in the case of corrosion of the tensile reinforcing steel bars, the failure mode varies from shear to bending state. The failure mode is significantly altered by changing the beam depth [14]. Shear failures occur without warning and previous symptoms. Studying the shear behavior of DBs is so complicated because shear forces are usually associated with flexural and axial forces.

A variant of genetic programming, namely gene expression programming (GEP) has been utilized by Gandomi et al. [15] to predict the shear strength of RC DBs. Kaya [16] determined the optimum horizontal and vertical reinforcement diameters of five different beams by using genetic algorithms due to the opening/height ratio, loading condition and the presence of spaces in the body. Yavuz [17] investigated the efficiency of artificial neural networks (ANNs) in predicting the shear strength of RC deep beams. He developed an ANN model using experimental data for deep beams from an existing literature database. The study showed that the ANN model provides acceptable predictions of the ultimate shear strength of RC deep beams. Senthil et al. [18] investigated the deep beams with an opening under static monotonic loading to demonstrate the accuracy and effectiveness of the finite element based numerical models using ABAQUS/CAE program and the experimental data available in the literature. In general, the numerical results accurately predicted the pattern of deformation and displacement and found in good agreement with the experiments. The study showed that a $25 \%$ increase in opening size resulted in an average shear strength reduction of $35 \%$ and a $10 \%$ increase in depth resulted in a $78 \%$ reduction in deflection. In another numerical study, Arabzadeh [19] analyzed RC DBs by using finite element analysis and a nonlinear analysis software (ANSYS Version 8).

Fiber theory is another useful method for analyzing $\mathrm{RC}$ members. This model has been used to analyze different types of RC members such as beams, columns, shear walls, and deck systems. Hashemi et al. [20] used this method to model bubble deck systems. In the fiber theory, the RC member is divided into several sub-elements which are composed of parallel layers. Park et al. [21] have used the fiber model to analyze the $\mathrm{RC}$ elements under cyclic loading. The fiber model ignores the slip between the reinforcing steel bar and concrete and it means that the theory is based on the perfect bond assumption [22]. Arsalan and Kiristioglu [23] studied the shear and flexural strengths of $\mathrm{RC}$ members. They used finite element analyses to investigate the influence of displacement ductility on concrete contribution to shear strength. Monti and Spacone [24] calculated the bond-slip relation between reinforcing steel bar and concrete in RC elements. Hashemi and Vaghefi [25], as well as Limkatanyu and Spacone [26], applied the Timoshenko beam theory instead of the Euler-Bernoulli beam theory in order to consider the effect of shear deformations. Because of the high sensitivity of RC DBs to the effect of shear deformations, the overall behavior of DBs has been studied in this paper and a new approach for the numerical analysis of DBs is proposed. The new method is based on fiber theory, but the difference is that the perfect bond assumption is removed in order to consider the interaction between reinforcing steel bar and concrete.

\section{Nonlinear modeling of RC DB with the interaction between reinforcing steel bar and concrete 2.1 Principles used in RC DB modeling}

According to the fiber theory, the $\mathrm{RC}$ member is divided into some smaller sub-elements longitudinally. It is assumed that each sub-element is composed of parallel layers. Concrete materials have been presented by some layers and the other layers present steel materials. The behavior of concrete and steel are assigned to each layer in accordance with the layer material type regardless of their interaction. In the base model of fiber theory, the interaction between reinforcing steel bar and concrete is ignored or in other words, it is based on perfect bond assumption. The theory which is used in the research reported in this paper is based on fiber theory but the difference is that the perfect bond assumption is removed and the possible effects of slip between reinforcing steel bar and concrete are considered. In order 
to consider the possibility of slipping between reinforcing steel bar and concrete, individual degrees of freedom have been assigned to each reinforcing steel bar. In fact, it is assumed that each reinforcing steel bar acts as a truss element which has 2 nodes with axial degrees of freedom. The concrete segment is assumed to acts as a 2 nodes beam element with individual degrees of freedom. The mentioned method has been used by Chargod et al. [27] in order to analyze the RC shear walls. As shown in Fig. 1, each subelement is composed of a concrete segment and $n$ number of steel reinforcing steel bar elements.

\subsection{Timoshenko and Euler-Bernoulli beam theories}

According to the researches carried out by Limkatanyu and Spacone [26] as well as Hashemi and Vaghefi [25], the formulations are rewritten by eliminating Euler-Bernoulli beam theory and substituting it with Timoshenko beam theory. The effect of slippage between reinforcing steel bars and surrounding concrete is considered by foreseeing the strain compatibility between reinforcing steel bars and concrete. In the Timoshenko beam theory, it is assumed that the cross-sections remain plane and are not necessarily perpendicular to the longitudinal axis during bending, but the shear deformations are neglected in Euler-Bernoulli beam theory and it is assumed that the plane sections remain plane and also perpendicular to the longitudinal axis after deformation. Euler-Bernoulli and Timoshenko beam theories have been compared and illustrated in Fig. 2 [28].

\subsection{Basic equations}

The stress values in the cross-section can be calculated by Eqs. (1) and (2) for uniaxial bending conditions at any position related to $\mathrm{x}$ position along the element.
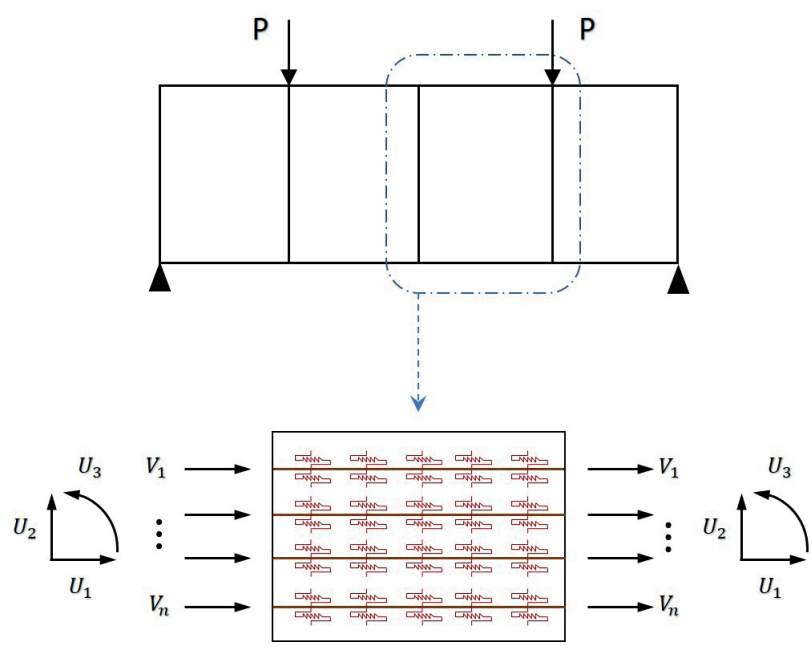

Fig. 1 Reinforced concrete DB numerical modeling
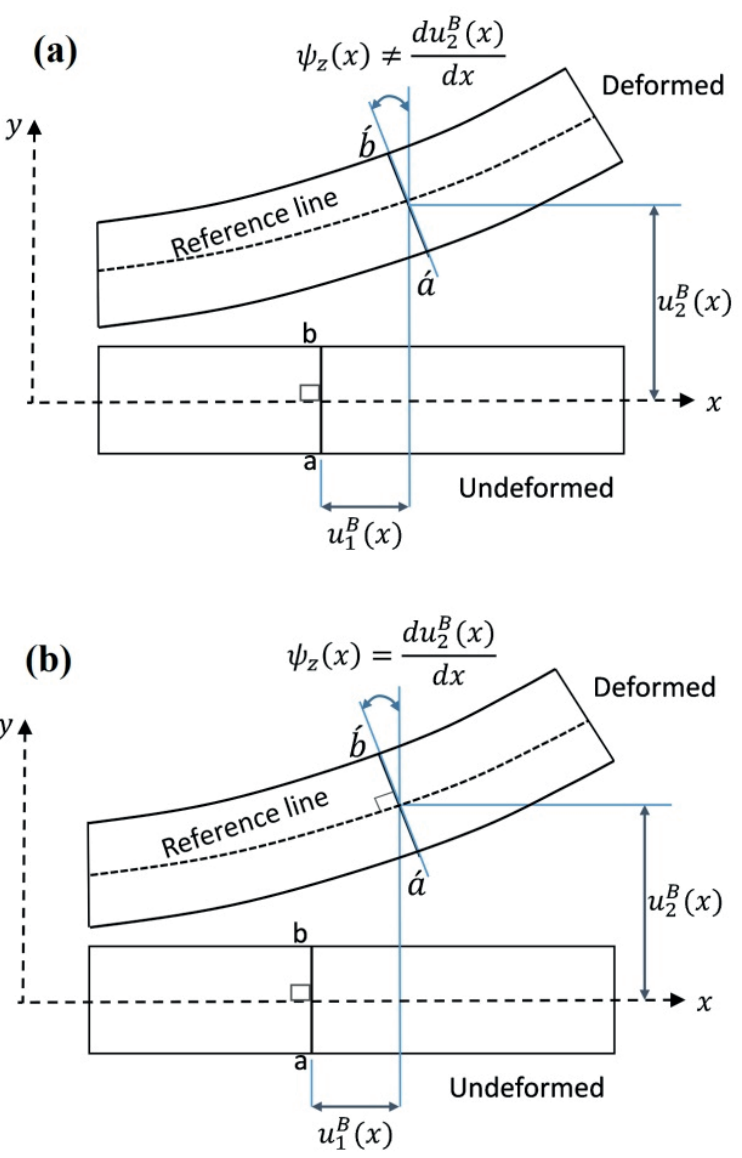

Fig. 2 Comparison between (a) Timoshenko beam theory and (b) EulerBernoulli beam theory

$\sigma_{x x}(x, y)=-E y \frac{d \psi_{z}(x)}{d x}$

$\sigma_{x y}(x, y)=G\left(\frac{\partial u_{x}(x, y)}{\partial y}+\frac{\partial u_{y}(x, y)}{\partial x}\right)$

Based on the Timoshenko beam theory Eq. (2) can be rewritten as follows:

$\sigma_{x y}(x, y)=G\left(-\psi_{z}(x)+\frac{d u_{2}^{B}(x)}{\partial x}\right)$,

where $\psi_{z}(x)$ represents the rotational deformation and $u_{2}^{B}(x)$ the represents the transversal displacement of the concrete element. $\sigma_{x x}$ and $\sigma_{x y}$ are defined as longitudinal and shear stresses in the section. $E, G, u_{x}$ and $u_{y}$ represent defined as modulus of elasticity, shear modulus, longitudinal displacement, and transversal displacement, respectively.

Bending moment about the z-axis (see Fig. 3) and shear force in the y-direction can be expressed as Eqs. (4) and (5), respectively.

$M_{z}(x)=-\int_{A} y \sigma_{x x} d A=E \frac{d \psi_{z}(x)}{d x} \int_{A} y^{2} d A=E I_{z} \frac{d \psi_{z}(x)}{d x}$ 


$$
\begin{aligned}
& V_{y}(x)=-\int \sigma_{x y} d_{A}=-\beta_{y} G_{\text {shear }}\left(-\psi_{z}(x)+\frac{d u_{2}^{B}(x)}{d x}\right) \int{ }_{A} d_{A} \\
& =-\beta_{y} G\left(-\psi_{z}(x)+\frac{d u_{2}^{B}(x)}{d x}\right) A=-\beta_{y} \sigma_{x y} A
\end{aligned}
$$

Where $\beta_{y}$ and $I_{z}$ present the shear correction factor and moment of inertia of the section, respectively.

By using relation $\sigma_{x y}=G \gamma_{y}$, which shows shear stressstrain relation in the y-direction, from Eq. (5) it can be concluded that:

$$
-\frac{V_{y}(x)}{\beta_{y} G A}=\frac{d u_{2}^{B}(x)}{d x}-\psi(x) \Rightarrow \gamma_{y}=\psi_{z}(x)-\frac{d u_{2}^{B}(x)}{d x} .
$$

Thus, the difference between $\frac{d u_{2}^{B}(x)}{d x}$ and $\psi_{z}(x)$ values in the section will result in the shear strain in the y-direction which has been neglected in the Euler-Bernoulli beam theory. Gruttmann and Wagner [29] have presented more details about employed shear correction factor.

As shown in Fig. 3, a length segment of an RC element is assumed as a combination of a length segment of a 2-node concrete element and $n$ number of reinforcing steel bar elements. A 2-node concrete element follows the Timoshenko beam theory to consider both cases of flexural and shear deformations. In fact, 2-node reinforcing steel bar elements are truss elements with axial degrees of freedom. Based on researches carried out by Hashemi and Vaghefi [30], the effect of bond force between the concrete and each longitudinal reinforcing steel bar is taken into account.

Because of the concrete element and the reinforcing steel bar's individual nodal degrees of freedom, the reinforcing steel bar's slippage is allowed to occur. According to small deformation assumptions, all equilibrium conditions are considered. Considering the axial equilibrium in the concrete element and steel reinforcing steel bars, as well as the transversal and moment equilibriums in the segment $d x$, leads to a matrix form of the relation given by Eq. (7).

$\partial_{B}^{T} \boldsymbol{D}_{B}(x)-\partial_{b}^{T} \boldsymbol{D}_{b}(x)-\boldsymbol{P}(x)=0$,

where: $\boldsymbol{D}_{\boldsymbol{B}}(x)=\{\overline{\boldsymbol{D}}(x): \overline{\overline{\boldsymbol{D}}}(x)\}^{T}$ represents the vector of RC element section forces, $\overline{\boldsymbol{D}}(x)=\left\{N(x) V_{y}(x) M_{y}(x)\right\}^{T}$ represents the vector of concrete element section forces, $\overline{\overline{\boldsymbol{D}}}(x)=\left\{N_{1}(x) \ldots N_{n}(x)\right\}^{T}$ represents the vector of reinforcing steel bar axial forces. Which has $n$ rows, $\boldsymbol{D}_{\boldsymbol{b}}(x)=\left\{\boldsymbol{D}_{\boldsymbol{b} 1}(x) \ldots \boldsymbol{D}_{\boldsymbol{b} \boldsymbol{n}}(x)\right\}^{T}$ represents the vector of section bond forces, $\boldsymbol{P}(x)=\left\{\begin{array}{lllll}0 & p_{y} & 0 & 0 & \ldots .0\end{array}\right\}^{T}$ represents the vector RC element force vector and $n$ represents the number of longitudinal reinforcing steel bars in the cross-section. $p_{y}$ represents the value of the external load. $\partial_{B}, \partial_{b}$ represent differential operators and given in Eq. (8) and (9).

$$
\begin{aligned}
& \partial_{B}=\left[\begin{array}{cc}
\bar{\partial}_{B} & 0 \\
0 & \overline{\bar{\partial}}_{B}
\end{array}\right], \bar{\partial}_{B}=\left[\begin{array}{ccc}
\boldsymbol{d} / \boldsymbol{d} \boldsymbol{x} & 0 & 0 \\
0 & \boldsymbol{d} / \boldsymbol{d} \boldsymbol{x} & -1 \\
0 & 0 & \boldsymbol{d} / \boldsymbol{d} \boldsymbol{x}
\end{array}\right] \\
& \overline{\bar{\partial}}_{B}=\left[\begin{array}{cccc}
\boldsymbol{d} / \boldsymbol{d} \boldsymbol{x} & 0 & \ldots & 0 \\
0 & \boldsymbol{d} / \boldsymbol{d} \boldsymbol{x} & \ldots & 0 \\
\ldots & \ldots & \ldots & \ldots \\
0 & 0 & \ldots & \boldsymbol{d} / \boldsymbol{d} \boldsymbol{x}
\end{array}\right]
\end{aligned}
$$

$$
\partial_{b}=\left[\begin{array}{ccccccc}
-1 & 0 & y_{1} & 1 & 0 & \ldots & 0 \\
-1 & 0 & y_{2} & 0 & 1 & \ldots & 0 \\
\ldots & \ldots & \ldots & \ldots & \ldots & \ldots & 0 \\
-1 & 0 & y_{n} & 0 & 0 & \ldots & 1
\end{array}\right]_{n^{*}(n+3)}
$$

As shown in Fig. $3, \boldsymbol{y}_{n}$ shows the distance of reinforcing steel bar number $n$ from the section reference axis. $\boldsymbol{d}_{\boldsymbol{B}}(x)=\{\overline{\boldsymbol{d}}(x): \overline{\overline{\boldsymbol{d}}}(x)\}^{T} \quad$ represents the RC element section deformation vector conjugate of $\boldsymbol{D}_{\boldsymbol{B}}(x)$. In which $\overline{\boldsymbol{d}}(x)=\left\{\varepsilon_{B}(x) \gamma_{y}(x) k_{B}(x)\right\}^{T} \quad$ contains concrete element section deformations and $\overline{\overline{\boldsymbol{d}}}(x)=\left\{\varepsilon_{1}(x) \ldots \varepsilon_{n}(x)\right\}^{T}$ contains the axial strain of the reinforcing steel bars. The displacement vector in the cross-section of the RC element is defined as $\boldsymbol{u}(x)=\{\overline{\boldsymbol{u}}(x): \overline{\overline{\boldsymbol{u}}}(x)\}^{T}$, which $\overline{\boldsymbol{u}}(x)=\left\{u_{B}^{1}(x) u_{B}^{2}(x) \psi_{z}(x)\right\}^{T}$ contains concrete element axial, transversal and rotational displacements, respectively. $\overline{\overline{\boldsymbol{u}}}(x)=\left\{u_{1}(x) \ldots u_{n}(x)\right\}^{T}$ contains the axial displacements of the reinforcing steel bars. According to the small deformation assumption, the Eq. (10) relates the element deformations to the element displacements.

$\boldsymbol{d}_{\boldsymbol{B}}(x)=\partial_{B} \boldsymbol{u}(x)$

The slip values of the reinforcing steel bars in the section of the RC element are determined by the following relation between the reinforcing steel bar and concrete element displacements:

$u_{b i}(x)=v_{i}(x)-u_{1}^{B}(x)+y_{i} \psi_{z}(x)$,

where $v_{i}(x)$ represents the reinforcing steel bar axial displacement and $u_{1}^{B}(x)$ represents the longitudinal displacement of the concrete element.

By introducing the bond deformation vector as $\boldsymbol{d}_{\boldsymbol{b}}(x)=\left\{u_{b 1}(x) \ldots u_{b n}(x)\right\}^{T}$, Eq. (11) can be written in the following matrix form:

$\boldsymbol{d}_{\boldsymbol{b}}(x)=\partial_{b} \boldsymbol{u}(x)$. 


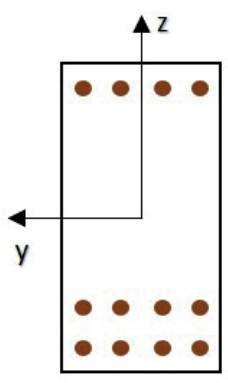

Cross Section

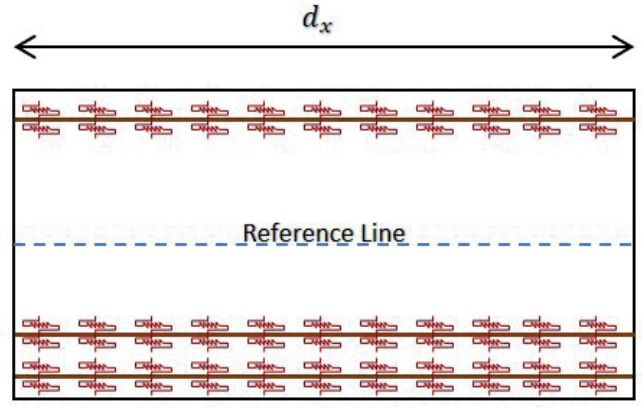

Infinitesimal Segment

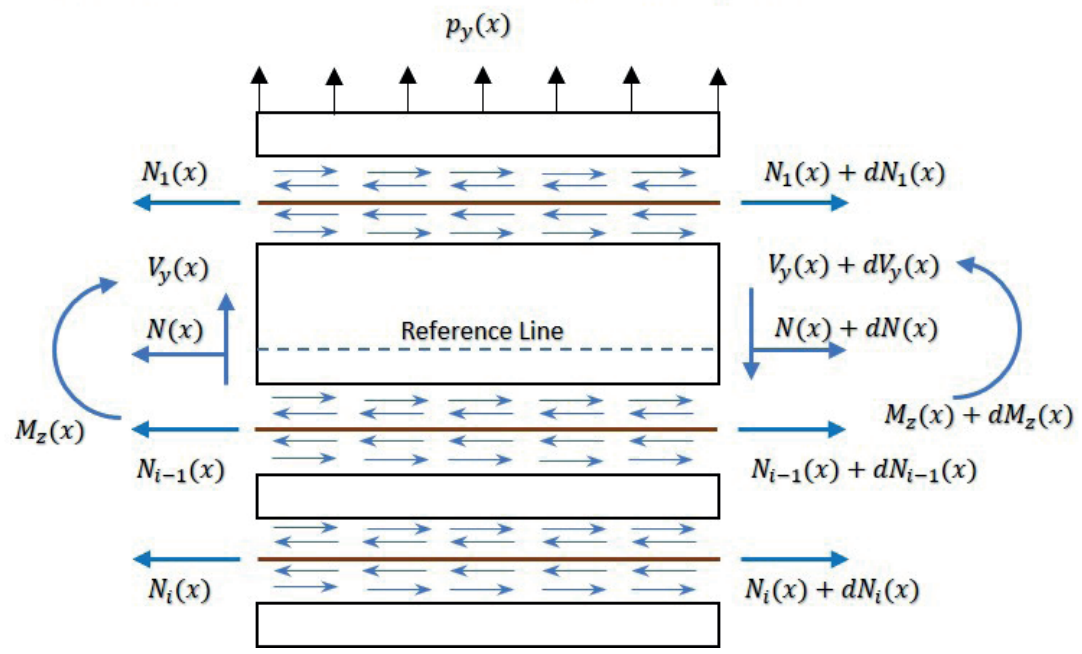

Fig. 3 Free body diagram of an infinitesimal segment of RC element

According to finite element formulation, a form of displacement is determined by using the principle of stationary potential energy. The RC element nodal displacement $(\boldsymbol{U})$, which is shown in Fig. 4, serves as primary unknown quantities of the element and the section displacement $\boldsymbol{u}(x)$ are related to it through the displacement shape function matrix $(N(x))$. The relation between nodal displacements and internal deformations can be written through the transformation matrix as Eqs. (13) to (16).

$\boldsymbol{d}_{\boldsymbol{B}}(x)=B_{B}(x) \boldsymbol{U}$

where:

$B_{B}(x)=\partial_{B} N(x)$,

and:

$\boldsymbol{d}_{\boldsymbol{b}}(x)=B_{b}(x) \boldsymbol{U}$,

where:

$B_{b}(x)=\partial_{b} N(x)$.

The nonlinear behavior of the $\mathrm{RC}$ element is derived from the nonlinear relation between the section forces $\left(\boldsymbol{D}_{B}(x), \boldsymbol{D}_{b}(x)\right)$ and the section deformations $\left(\boldsymbol{d}_{B}(x), \boldsymbol{d}_{b}(x)\right)$ through section and bond stiffness matrices $\left(\boldsymbol{K}_{B}(x), \boldsymbol{K}_{b}(x)\right)$. The section stiffness matrix contained the axial, shear and bending stiffnesses of the concrete element $(E A(x), G A(x)$ and $E I(x))$ and also the axial stiffness of the reinforcing steel bars $\left(E_{n} A_{n}(x)\right)$. The bond stiffness matrix is diagonal and included the slope of the bond force-slip relationship of each reinforcing steel bar $\left(\boldsymbol{K}_{\boldsymbol{b n}}(\boldsymbol{x})\right)$. The section stiffness matrix is derived by using the fiber section method. In the mentioned method, the stress-strain relationships of concrete and steel materials are needed. The bond stiffness matrix is derived through the bond stress-slip relation and perimeter of each reinforcing steel bar. Based on finite element formulation, the stiffness matrix of the RC element with the bond-slip effect can be derived through the summation of two stiffness matrices. Thus, it can be written in the form of Eq. (17).

$$
\begin{aligned}
& \boldsymbol{K}(x)=\boldsymbol{K}_{B}+\boldsymbol{K}_{b}=\int{ }_{L} \boldsymbol{B}_{B}^{T}(x) \boldsymbol{K}_{B}(x) \boldsymbol{B}_{B}(x) d x \\
& +\int{ }_{L} \boldsymbol{B}_{b}^{T}(x) \boldsymbol{K}_{b}(x) \boldsymbol{B}_{b}(x) d x,
\end{aligned}
$$

where $\boldsymbol{K}$ represents the RC element stiffness matrix, $\boldsymbol{Q}$ represents the resisting force vector of the element, $\boldsymbol{K}_{B}$ and $\boldsymbol{K}_{b}$ represent the element and bond contributions to the stiffness matrix, respectively. 


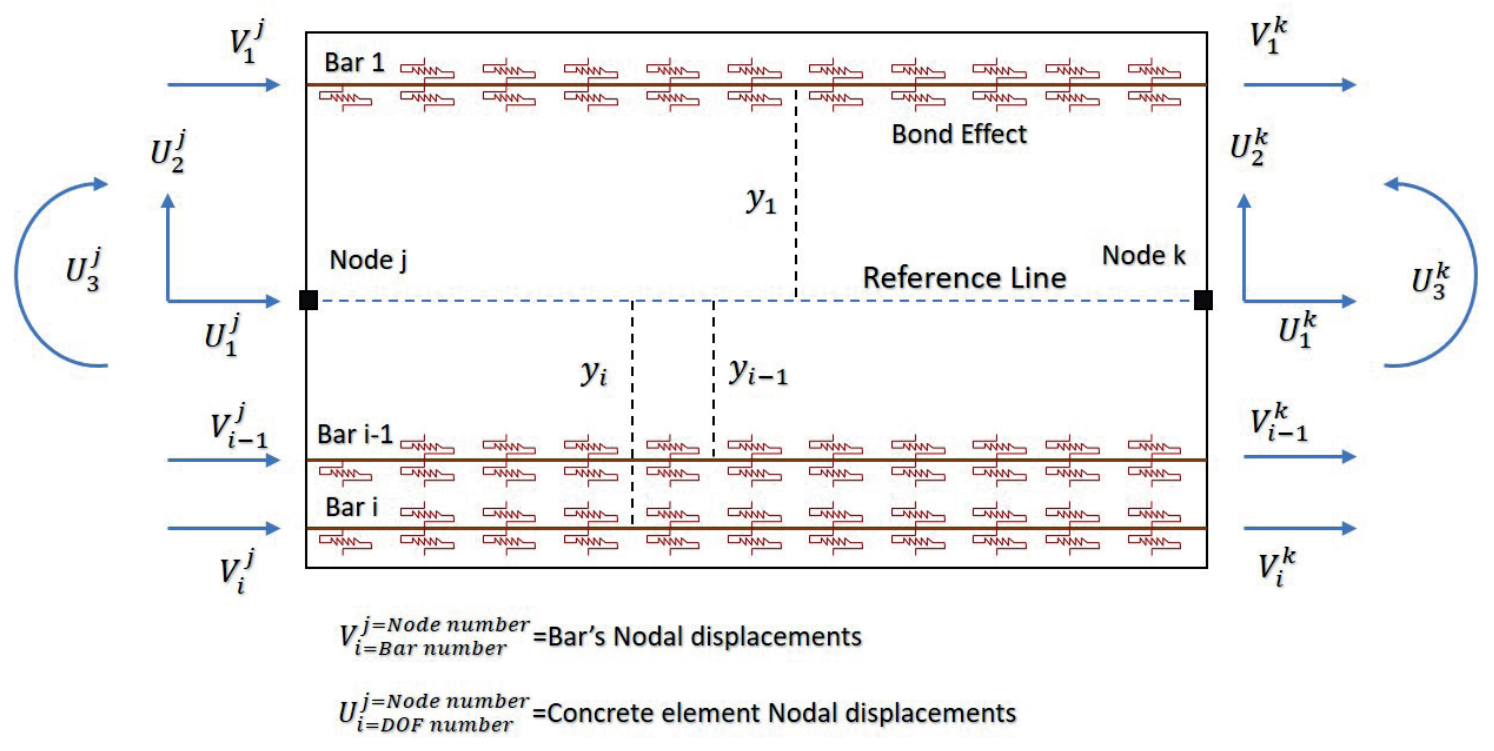

Fig. 4 Reinforced concrete element

The relationship among the external load vector, the internal resisting force vector and the nodal displacement vector in the nonlinear analysis algorithm are written as Eq. (18).

$$
\begin{aligned}
& \boldsymbol{K} \Delta \boldsymbol{U}=\boldsymbol{P}-\int{ }_{L} B_{B}^{T}(x) \boldsymbol{D}_{B}(x) d x-\int{ }_{L} B_{b}^{T}(x) \boldsymbol{D}_{b}(x) d x \\
& =\boldsymbol{P}-\boldsymbol{Q}=\boldsymbol{P}-\left(\boldsymbol{Q}_{B}+\boldsymbol{Q}_{b}\right),
\end{aligned}
$$

where $\boldsymbol{Q}_{B}$ and $\boldsymbol{Q}_{b}$ represent the element and bond contributions to the resisting force vector, respectively. At each load step of the nonlinear analysis, the resisting force vector of the section is driven according to existing deformations in each section of the element. Thereby, numerical integration methods have been used in order to derive the resisting force vector of the element. At each load step, the result of $\boldsymbol{P}-\boldsymbol{Q}$ is the residual force vector and converges to a zero vector after some iterations.

A computer program created in MATLAB software [31] was used by the authors.

\section{The applied constitutive laws for materials}

\subsection{The applied constitutive law for Reinforcing steel bars}

The relation between stress and strain in concrete material defined by Giuffre-Menegoto-Pinto model has been used in the modeling of the DBs. As shown in Fig. 5, the stress-strain curve defines the steel behavior by two lines and the isotropic strain hardening part is modified by Filippou et al. [32]. This model also has a good agreement with experimental results from cyclic tests of reinforcing steel bars [33].

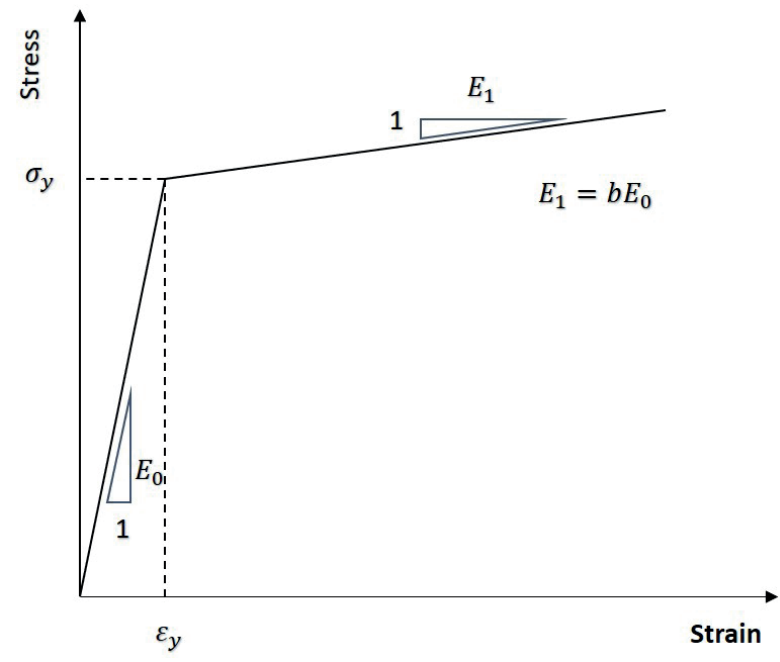

Fig. 5 Stress-strain relation of reinforcing steel bars

\subsection{The applied constitutive law for concrete}

To model the behavior of the concrete elements in the compression region, the constitutive law proposed by Karsan and Jirsa [34] is applied. The Concrete compressive stressstrain curve is shown in Fig. 6.

Park et al. [21] proposed a monotonic envelope curve which is able to express the behavior of confined concrete. It was developed by Scott et al. [35]. This model has been adopted in numerical models because of its computational efficiency and simplicity.

In modeling, it is assumed that the concrete behavior is linear elastic in the tension region before the tensile strength and, beyond that, the tensile stress is reduced linearly with increasing tensile strain. In addition, it is assumed that the ultimate state of tension behavior occurs when tensile strain exceeds the value which is given in Eq. (19). 


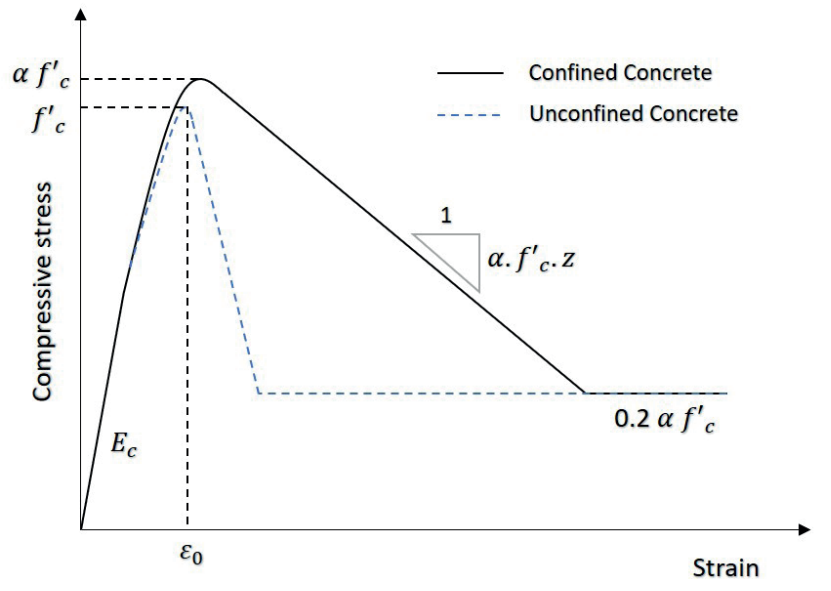

Fig. 6 Concrete compressive stress-strain curve

$\boldsymbol{\mu}_{u t}=2 \times\left(\frac{\boldsymbol{G}_{f}}{\boldsymbol{f}_{t}}\right) \times \boldsymbol{L} \boldsymbol{n}\left(\frac{3}{\boldsymbol{L}}\right) /(3-\boldsymbol{L})$,

where $\boldsymbol{G}_{f}$ represents the fracture energy that is dissipated in the formation of cracks of unit length per unit thickness which is considered as a material property and $\boldsymbol{L}$ represents the element length in $\mathrm{mm}$. $\boldsymbol{f}_{t}$ represents the concrete tensile strength.

Based on the research carried out by Welch and Haisman [36], the value of $\boldsymbol{G}_{f} / \boldsymbol{f}_{t}$ is in the range of $0.005-$ 0.01 for normal strength concrete. In this research, for the average value of 0.0075 is assumed.

\subsection{Shear stress-strain relation}

Modified compression field theory (MCFT) for shear stress-strain model has been adopted to define the shear behavior of RC DBs under shear forces. The main idea proposed by Vecchio and Collins [37] and later developed by Collins and Mitchell [38] and Bentz [39]. According to the MCFT, shear stress-strain model depends on various parameters such as the percentage of reinforcing steel bar in different directions, the compressive strength of concrete and the tensile strength of reinforcing steel bars. Thus, each RC element has its unique shear stressstrain model. This model is based on the continuum mechanics approach. The Membrane-2000 software [40], which is based on the MCFT has been employed. This software receives effective variables of RC elements as input and generates the stress-strain diagrams, so it is beneficial to generate the shear stress-strain diagram of RC elements which is complicated to achieve. Fig. 7 shows a shear stress-strain model which is generated by Membrane-2000.

\subsection{Bond stress-slip relation}

The model proposed by Eligehausen et al. [41] for the bondslip effect between concrete and reinforcing steel bars is adapted to present the bond stress-slip relation (see Fig. 8). Bond slip is the relative displacement between the reinforcing steel bar and the concrete. Bond stress is referred to as the shear stress acting parallel to an embedded reinforcing steel bar on the contact surface between the concrete and the reinforcing steel bars. This model considers the effect of many variables, such as the compressive strength of the concrete, the height and spacing of the lugs on the reinforcing steel bar, the diameter of reinforcing steel bar, the thickness of the concrete cover and the end bar hooks.

\section{Numerical investigation}

An investigation has been done on the overall behavior of two RC DBs in order to evaluate the theory and the effect of shear deformations. The aforementioned relations and theories have been applied to make numerical models of specimens in MATLAB software. For each specimen, the analytical results have been compared with experimental pushover results separately.

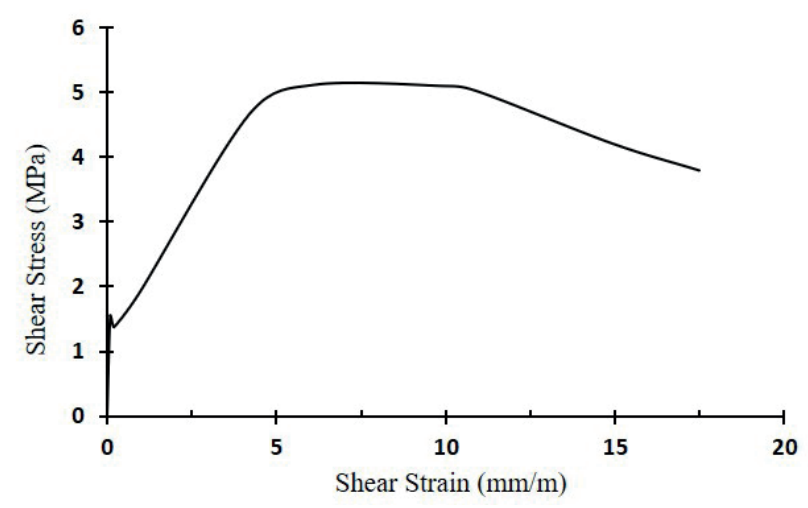

Fig. 7 Shear stress-strain according to the MCFT, generated by Membrane-2000

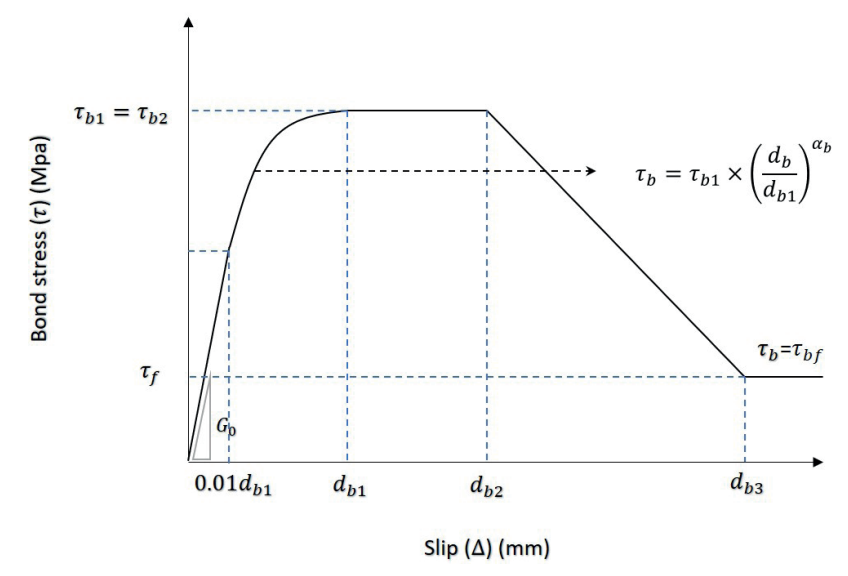

Fig. 8 Bond stress-slip relation 


\subsection{Description of the tested specimens}

Salamy et al. [12] have tested a group of simply supported RC DBs at the Public Works Research Institute (PWRI) and Kyushu Institute of technology. The experimental pushover results recorded for two beams have been employed in this research. The ratio of shear span to effective depth is 1.5 in both beams, so they are categorized as RC DBs. The specimens have been loaded on two symmetric points by a hydraulic jack. Fig. 9 shows the cross-section area and geometric parameters of the tested beams. The dimensions and specifications of the DBs are given in Table 1.

The details of reinforcement and tensile strength of reinforcing steel bars are presented in Table 2 .

Where the percentage of longitudinal steel and stirrups are donated by $\rho_{x}$ and $\rho_{y}$ respectively.

\subsection{Evaluation of the obtained results}

Analytical models of specimens have been made and the mentioned constitutive models have been used to define the behavior of materials and interaction between them.

Table 1 Dimensions and specifications of specimens (all dimensions in $\mathrm{mm}$ ) [12]

\begin{tabular}{lcc}
\hline & Specimen 1 & Specimen 2 \\
\hline$a / d$ & 1.5 & 1.5 \\
$L$ & 6650 & 3750 \\
$c$ & 1050 & 750 \\
$a$ & 2100 & 1500 \\
$d$ & 1400 & 1000 \\
$h$ & 1505 & 1105 \\
$b$ & 840 & 600 \\
$b_{s}$ & 350 & 250 \\
$f_{c}(\mathrm{MPa})$ & 23.5 & 28.7 \\
\hline
\end{tabular}

Table 2 Details and specimens of reinforcement [12]

\begin{tabular}{lcc}
\hline & Specimen 1 & Specimen 2 \\
\hline$\rho_{y}$ & 0.4 & 0.4 \\
$\rho_{x}$ & 2.05 & 2.04 \\
$F_{y}(\mathrm{MPa})$ & 397.5 & 398 \\
Stirrups & $\phi 16 @ 120 \mathrm{~mm}$ & $\phi 13 @ 100 \mathrm{~mm}$ \\
\hline
\end{tabular}

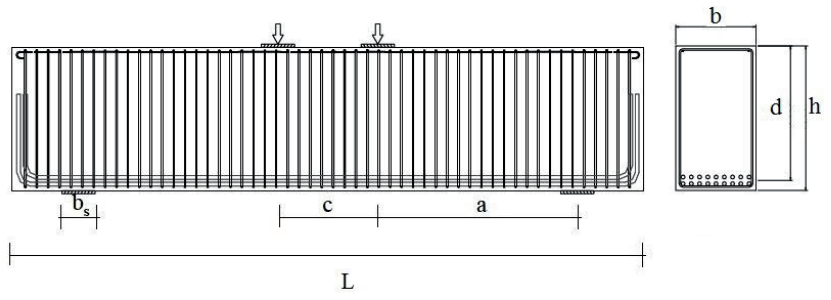

Fig. 9 The geometry of specimens [12]
For each specimen, in order to monitor the sensitivity of the overall behavior to the effect of shear deformations, the formulation of Timoshenko and Euler-Bernoulli beam theories are applied in each analytical model separately. As shown in Figs. 10 and 11, to evaluate the theories, total load versus mid-span deflection curves have been obtained from analytical results and have been compared with the experimental test results for each specimen.

As depicted in Fig. 10, the polynomial degree 3 trendline type matches very well with the variation of the simulated load-deflection response curve. For the Specimen 1, the simulation applying the Timoshenko beam theory shows the relation give in Eq. (20) with a determination factor of $R^{2}=0.9945$.

$P=0.0016 \delta^{3}-0.0755 \delta^{2}+1.311 \delta(P$ in $\mathrm{kN})$,

where:

$P$ : Total load in $\mathrm{kN} / \mathrm{mm}$,

$\delta$ : Midspan deflection.

As illustrated in Fig. 11, the polynomial degree 3 trendline type matches very well with the variation of the simulated load-deflection response curve. For the Specimen 2, the simulation applying the Timoshenko beam theory shows the relation give in Eq. (21) with a determination factor of $R^{2}=0.9945$.

$$
P=0.0025 \delta^{3}-0.0881 \delta^{2}+1.0666 \delta(P \text { in } \mathrm{kN})
$$

The comparison between the analytical results and experimental results shows that applying EulerBernoulli beam theory and neglecting the effect of shear

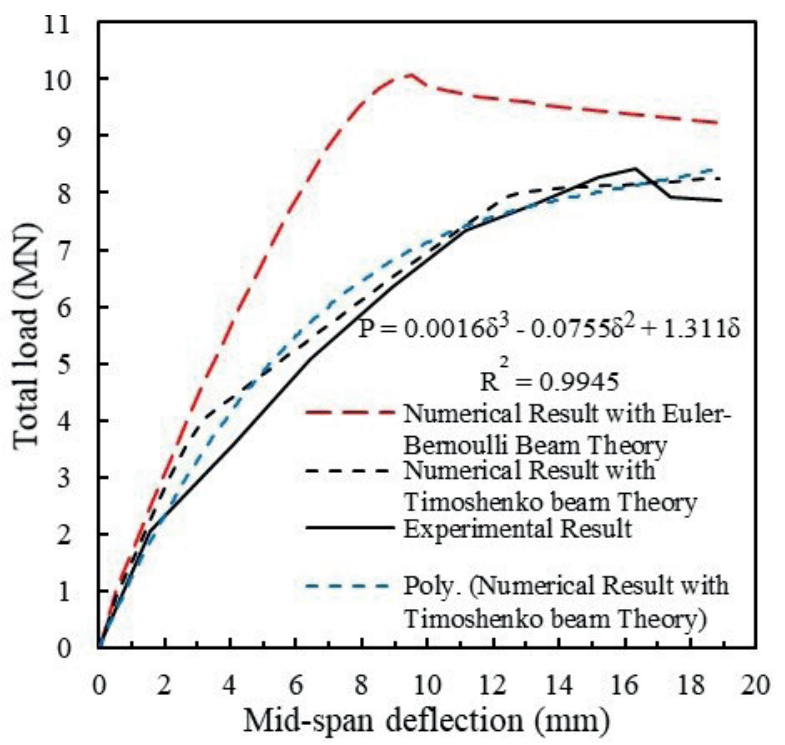

Fig. 10 Comparison of analytical results with experimental behavior for specimen 1 


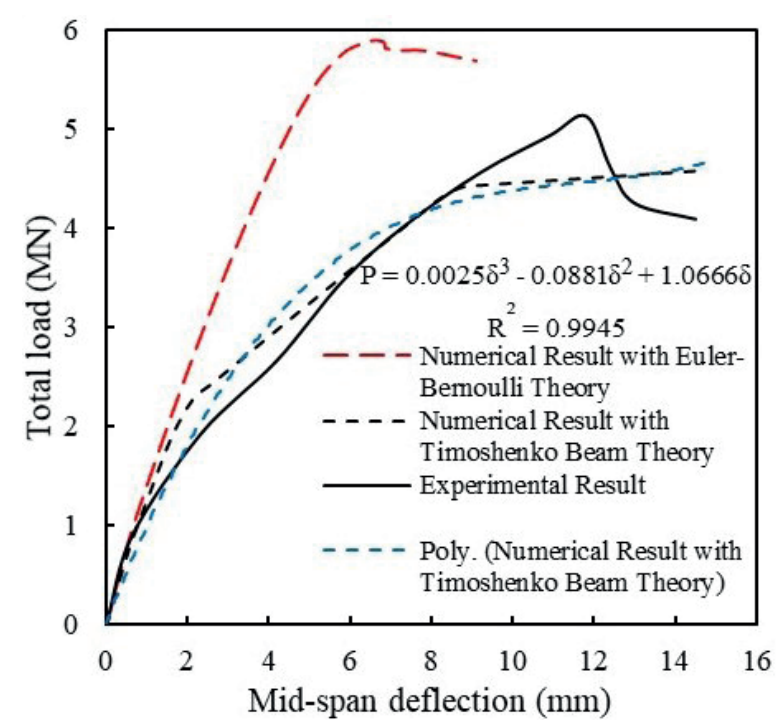

Fig. 11 Comparison of analytical results with experimental behavior for Specimen 2

deformations leads to overestimating the stiffness and ultimate resistance in both examined specimens. Although the corresponding displacement to ultimate resistance will be underestimated, the analytical results by applying the Timoshenko beam theory and considering the effect of

\section{References}

[1] Collins, M. P., Mitchell, D., Bentz, E. C. "Shear design of concrete structures", The Structural Engineer, 86(10), pp. 32-39, 2008.

[2] Arabzadeh, A., Aghayari, R., Rahai, A. R. "Investigation of experimental and analytical shear strength of reinforced concrete deep beams", International Journal of Civil Engineering, 9(3), pp. 207-214, 2011. [online] Available at: http://ijce.iust.ac.ir/article-1478-en.html

[3] Niranjan, B. R., Patil, S. S. "Analysis of RC Deep Beam by Finite Element Method", International Journal of Modern Engineering Research (IJMER), 2(6), pp. 4664-4667, 2012. [online] Available at: http://www.ijmer.com/papers/Vol2_Issue6/ET2646644667.pdf

[4] Rogowsky, D. M., MacGregor, J. G., Ong, S. Y. "Tests of reinforced concrete deep beams", ACI Journal Proceedings, 83(4), pp. 614 623, 1986.

[5] Hsu, T. T. C. "Unified Theory of Reinforced Concrete", CRC Press, Boca Raton, FL, USA, 2017.

[6] ACI "ACI 318M-14: International Organization for Standardization, Building Code Requirements for Structural Concrete and Commentary", American Concrete Institute, Farmington Hills, MI, USA, 2014.

[7] Ismail, K. S. "Shear Behaviour of Reinforced Concrete Deep Beams", PhD dissertation, University of Sheffield, 2016.

[8] Tuchscherer, R. G., Birrcher, D. B., Williams, C. S., Deschenes, D. J., Bayrak, O. "Evaluation of existing strut and tie methods and recommended improvements", ACI Structural Journal, 111(6), pp. 1451-1460, 2014. shear deformations yields to a good agreement with the experimental test results. Therefore, the effect of shear deformations is unneglectable in the analysis of RC DBs.

\section{Conclusions}

In fiber theory, the effect of shear deformations is ignored in most numerical nonlinear methods and they are usually based on the perfect bond assumption between reinforcing steel bars and surrounding concrete. In this research, the effect of interaction between reinforcing steel bar and concrete and also shear deformations have been considered in the formulation to make a numerical model which is based on fiber theory. The proposed model is useful to analyze the RC elements especially for RC DBs and shear walls which have a high sensitivity to the effect of shear deformations due to D-regions. The formulation is based on displacement and shape functions are applied to define the internal displacements in terms of nodal displacement. The reliability of the method is assessed through the experimentally tested specimens and a good agreement between numerical simulation and the experimental result is obtained for both cases of stiffness and strength.

[9] Almási, J. "Cracks as important constituents of strut and tie models", Periodica Polytechnica Civil Engineering, 36(3), pp. 251-270, 1992.

[10] Smith, K. N., Vantsiotis, A. S. "Shear strength of deep beams", ACI Journal Proceedings, 79(3), pp. 201-213, 1982.

[11] Breña, S. F., Roy, N. C. "Evaluation of load transfer and strut strength of deep beams with short longitudinal bar anchorages", ACI Structural Journal, 106(5), pp. 678-689, 2009.

[12] Salamy, M. R., Kobayashi, H., Unjoh, S. "Experimental and Analytical Study on RC Deep Beams", Asian Journal of Civil Engineering, 6(5), pp. 409-421, 2005.

[13] Yu, L., François, R., Gagné, R. "Mechanical performance of deep beams damaged by corrosion in a chloride environment", European Journal of Environmental and Civil Engineering, 22(5), pp. 523$545,2018$.

https://doi.org/10.1080/19648189.2016.1210033

[14] Ramadan, A. I., Aly Abd-Elshafy, A. G. "Statistical Prediction Equations for RC Deep beam without stirrups", In: International Congress and Exhibition "Sustainable Civil Infrastructures: Innovative Infrastructure Geotechnology, GeoMEast 2017", Sharm El Sheikh, Egypt, 2017, pp. 329-349, 2017.

[15] Gandomi, A. H., Yun, G. J., Alavi, A. H. "An evolutionary approach for modeling of shear strength of RC deep beams", Materials and Structures, 46, pp. 2109-2119, 2013. https://doi.org/10.1617/s11527-013-0039-z

[16] Kaya, M. "Developing a new mutation operator to solve the RC deep beam problems by aid of genetic algorithm", Computers and Concrete, 22(5), pp. 493-500, 2018. https://doi.org/10.12989/cac.2018.22.5.493 
[17] Yavuz, G. "Shear strength estimation of RC deep beams using the ANN and strut-and-tie approaches", Structural Engineering and Mechanics, 57(4), pp. 657-680, 2016. https://doi.org/10.12989/sem.2016.57.4.657

[18] Senthil, K., Gupta, A., Singh, S. P. "Computation of stress-deformation of deep beam with openings using finite element method", Advances in Concrete Construction, 6(3), pp. 245-268, 2018. https://doi.org/10.12989/acc.2018.6.3.245

[19] Arabzadeh, A., Dhir, R. K., Newlands, M. D., Whyte, A. "Analysis of an RC simply supported deep beam with nonlinear computer program", In: Application of Codes, Design and Regulations: Proceedings of the International Conference held at the University of Dundee, Dundee, Scotland, UK, 2005, pp. 671-676.

[20] Hashemi, S. S., Sadeghi, K., Vaghefi, M., Siadat, S. A. "Evaluation of ductility of RC structures constructed with bubble deck system", International Journal of Civil Engineering, 16, pp. 513-526, 2018. https://doi.org/10.1007/s40999-017-0158-y

[21] Park, R., Kent, D. C., Sampson, R. A. "Reinforced Concrete Members with Cyclic Loading", Journal of the Structural Division, 98(7), pp. 1341-1360, 1972.

[22] Valles, R. E., Reinhorn, A. M., Kunnath, S. K., Li, C., Madan, A. "IDARC 2D Version 6.0 July 2004 user's guide", National Science Foundation, Arlington, VA, USA, ,1996.

[23] Arslan, G., Kiristioglu, I. "Influence of Displacement Ductility on Concrete Contribution to Shear Strength", Periodica Polytechnica Civil Engineering, 60(3), pp. 379-386, 2016. https://doi.org/10.3311/PPci.7605

[24] Monti, G., Spacone, E. "Reinforced Concrete Fiber Beam Element with Bond-Slip", Journal of Structural Engineering, 126(6), pp. 654-661, 2000. https://doi.org/10.1061/(ASCE)0733-9445(2000)126:6(654)

[25] Hashemi, S. S., Vaghefi, M. "Investigation of bond slip effect on the PM interaction surface of RC columns under biaxial bending", Scientia Iranica A, 22(2), pp. 388-399, 2015. [online] Available at: http://scientiairanica.sharif.edu/article_1873.html

[26] Limkatanyu, S., Spacone, E. "Reinforced Concrete Frame Element with Bond Interfaces. I: Displacement-Based, Force-Based, and Mixed Formulations", Journal of Structural Engineering, 128(3), pp. 346-355, 2002. https://doi.org/10.1061/(ASCE)0733-9445(2002)128:3(346)

[27] Chargoad, H. Z., Hashemi, S. S., Vaghefi, M. "Cyclic Analysis of RC Shear Walls, Considering Bar-Concrete Interaction", Journal of Seismology and Earthquake Engineering, 18(2), pp. 131-139, 2016. [online] Available at: http://www.jsee.ir/index.php/jsee/article/ view/441

[28] Kwon, Y. W., Bang, H. "The finite element method using MATLAB", CRC Press, Boca Raton, FL, USA, 2000.
[29] Gruttmann, F., Wagner, W. "Shear correction factors in Timoshenko's beam theory for arbitrarily shaped cross-sections", Computational Mechanics, 27, pp. 199-207, 2001. https://doi.org/10.1007/s004660100239

[30] Hashemi, S. S., Vaghefi, M. "Investigation of the effect of a bar's inadequate embedded length on the PM interaction curve of reinforced concrete columns with rectangular sections", Turkish Journal of Engineering and Environmental Sciences, 36(2), pp. 109-119, 2012.

https://doi.org/10.3906/muh-1103-5

[31] MathWorks "MATLAB, (Version 8.3.0.532)", Natick, MA, USA, 2014.

[32] Filippou, F. C., Popov, E. P., Bertero, V. V. "Effects of bond deterioration on hysteretic behavior of reinforced concrete joints", Earthquake Engineering Research Center, University of California, Berkeley, CA, USA, Rep. UCB/EERC-83/19, 1983.

[33] Gomes, A., Appleton, J. "Nonlinear cyclic stress-strain relationship of reinforcing bars including buckling", Engineering Structures, 19(10), pp. 822-826, 1997. https://doi.org/10.1016/S0141-0296(97)00166-1

[34] Karsan, I. D., Jirsa, J. O. "Behavior of concrete under compressive loadings", Journal of the Structural Division, 95(12), pp. 25432564, 1969.

[35] Scott, B. D., Park, R., Priestley, M. J. N. "Stress-strain behavior of concrete confined by overlapping hoops at low and high strain rates", ACI Journal Proceedings, 79(1), pp. 13-27, 1982.

[36] Welch, G. B., Haisman, B. "Fracture Toughness Measurements of Concrete", University of New South Wales, Sidney, NSW, Australia, Rep. R-42, 1969.

[37] Vecchio, F. J., Collins, M. P. "The modified compression-field theory for reinforced concrete elements subjected to shear", ACI Journal Proceedings, 83(2), pp. 219-231, 1986.

[38] Collins, M. P., Mitchell, D. "Prestressed concrete structures", Englewood Cliffs, Prentice Hall, Upper Saddle River, NJ, USA, 1991.

[39] Bentz, E. C. "Explaining the Riddle of Tension Stiffening Models for Shear Panel Experiments", Journal of Structural Engineering, 131(9), pp. 1422-1425, 2005. https://doi.org/10.1061/(ASCE)0733-9445(2005)131:9(1422)

[40] Bentz, E., Collins, M. P. "Response-2000, Shell-2000, Triax-2000, Membrane-2000 User Manual", University of Toronto, Toronto, Canada, 2001. [online] Available at: http://www.ecf.utoronto.ca/ $\sim$ bentz/manual2/final.pdf

[41] Eligehausen, R., Popov, E. P., Bertero, V. V. "Local bond stressslip relationships of deformed bars under generalized excitations", In: Proceedings of the 7th European Conference on Earthquake Engineering, Athens, Greece, 1982, pp. 69-80. https://oi.org/10.18419/opus-415 